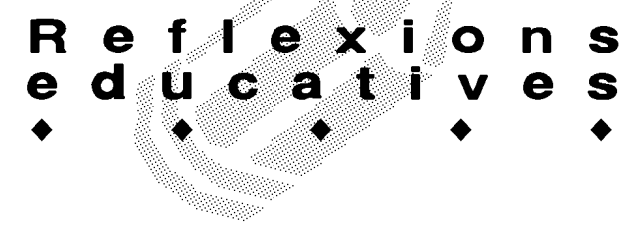

\title{
ELS NOSTRES VELLS MESTRES
}

\author{
Jordi Solé Blanch. Professor associat. Departament de Pedagogia. URV.
}

A mesura que el temps ens va fent homes i dones madurs ens adonem que, les coses que veiem ara, no són tan grans com les que es veien amb la mirada del nen o la nena que vam ser. Tanmateix, hi ha gestos, geografies, grans descobriments i jocs infantils que conservem en el record amb l'emoció quasibé intacta de quan érem petits. Alguns d'ells estan estretament vinculats a les primeres experiències viscudes a l'escola $i$ els seus mestres.

Per a un grup de preescolar d'una escola urbana de principis dels anys 80 l'aprenentatge dels nombres i les lletres va representar un moment molt important en les seves vides. Aquella setmana conservaria per sempre el seu to cerimoniós. Primer va ser l'anunci, amb el qual s'avisava als preescolars que un d'aquells dies coneixerien les grafies de l'abecedari. Després, la solemnitat amb què, un bon matí, havent assegut els nens i nenes a terra de cara la pissarra, la mestra agafaria els guixos de diferents colors que guardava dins d'una caixa de fusta per dibuixar amb traç parsimoniós aquells símbols plens de misteri que haurien de servir per anomenar les coses i els primers pensaments.

El ritual es repetia cada any en mans d'aquells sacerdots de l'escriptura, conscients de l'abast de la seva missió pedagògica. Moltes generacions convertirien aquesta experiència en la metàfora infantil del seu pas per l'escola. Després arribarien els rigors de la cal-ligrafia, però l'acte inaugural amb què la mestra va dibuixar la sonoritat de cada lletra a la pissarra representaria per a molts el primer contacte amb la totalitat de l'estètica i, per tant, de la bellesa.

De mestres se'n tenen molts al llarg de la vida (HARO TECGLEN, 1996). A uns se'ls admira i se'ls estima, a d'altres només hi ha temps per admirar-los, també per avorrir-los. Albert Camus (1994), quan relatava la seva biografia tràgicament interrompuda, escrivia que un nen no és res per si mateix: són els seus pares qui el representen. Per ells es defineix, per ells és definit als ulls del món. A través d'ells se sent jutjat de veritat, és a dir, jutjat sense poder apel-lar. Jo penso que el mestre o la mestra és el primer que t'ofereix la possibilitat d'apel-lar, de revelar la teva veritat. Sempre s'ha dit que l'essència de l'ofici del magisteri és precisament aquesta, tractar constantment d'atendre l'objectiu de la plenitud humana i la naturalesa dels nostres alumnes en la recerca desesperada de la veritat (BLOOM, 1989).

Després d'un curs de disciplines i sabers acadèmics, però també de tensions profundes i contradictòries, un mestre passa i deixa la seva empremta en la vida dels seus alumnes.

Sempre n'hi ha algun que, enmig d'un entorn innocu i insubstancial, aixeca el seu altar de persona íntegra $\mathrm{i}$ sencera per no ser oblidada mai més (SÁBATO, 1999). A molts ens acompanyarà la resta de les nostres vides aquell consell meditat, la paraula oportuna o el seu gest decisiu que hauria de modificar el nostre destí de nens o adolescents contrariats.

Caldria recórrer al mite de Sísif per entendre aquest ofici (CAMUS, 1996). Any rere any, generació rere generació, s'arrossega la pedra dels cursos pensant a millorar l'espècie humana. Sóc conscient que per a molts aquest trànsit de pujar la pedra fins al cim de la muntanya per veure-la caure de nou és viscut com un treball inútil i sense esperança, però d'altres imaginen Sísif content: l'esforç mateix per arribar al cim és suficient per omplir el seu anhel.

Continuo llegint El Primer Hombre d'Albert Camus i les descripcions que realitza del mestre a qui tant deu bé podrien servir per a tots aquells que estimen apassionadament el seu treball.

"En la clase del señor Germain (...) la escuela alimentaba en ellos un hambre más esencial todavía para el niño que para el hombre, que es el hambre de descubrir. En las otras clases les enseñaban, sin duda, muchas cosas, pero un poco como se ceba un ganso. Les presentaban un alimento ya preparado rogándoles que tuvieran a bien tragarlo. En la clase del señor Germain sentian por primera vez que existian y que eran objeto de la más alta consideración: se los consideraba dignos de descubrir el mundo. Más aún, el maestro no se dedicaba solamente a enseñarles lo que le pagaban para que enseñara: los acogía con simplicidad en su vida personal, la vivía con ellos contándoles su infancia y la historia de otros niños que habian conocido, les exponía sus propios puntos de vista, no sus ideas, pues siendo, por ejemplo, anticlerical como muchos de sus colegas, nunca decía en clase una sola palabra contra la religión ni contra nada de lo que podía 


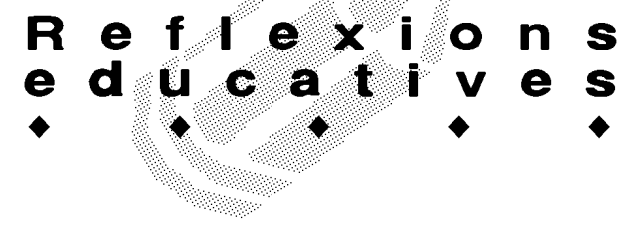

ser objeto de una elección o de una convicción, y en cambio condenaba con la mayor energía lo que no admitía discusión: el robo, la delación, la indelicadeza, la suciedad"(p. 128-129).

Però els esforços, el treball i, molt sovint, el cor generós d'aquests mestres poden córrer el perill de no continuar vius en els petits escolars. Fa uns anys, l'escriptor gallec Manuel Rivas (1998) va escriure un conte molt il.lustratiu en aquest sentit. Poc després, l'adaptació al cinema de La lengua de las mariposas (CUERDA, 1999) ens deixaria una imatge pertorbadora: la mirada d'un nen forçat a odiar qui li havia obert les portes al món mentre crida: "AAsesino!, jRojo!, ; Tilonorrinco!".

"Cuando los camiones arrancaron, cargados de presos, yo fui uno de los niños que corrieron detrás, tirando piedras. Buscaba con desesperación el rostro del maestro para llamarle traidor y criminal. Pero el convoy era ya una nube de polvo a lo lejos y yo, en medio de la Alameda, con los puños cerrados, sólo fui capaz de murmurar con rabia: "'Sapo!. ;Tilonorrinco! jlris!'

L'escena és dramàtica, però alhora esperançadora. No pels insults, òbviament, sinó per aquella paraula "tilonorrinco", que el nen havia après en una de les classes del vell mestre. Enmig de l'escarni, aquella paraula que apareix sense avís i llança junt amb la pedra el nen innocent, indica que les ensenyances del mestre, en un punt, romanen amb ell. I és aquí on resideix l'esperança.

No sé si és just citar aquests mestres ideals, com seguiria fent-ho amb Marta Mata, Maria Antònia Canals, Anna Maria Roig -les tres mestres que junt amb Jordi Cots, Pere Darder, Enric Lluch i amb el suport de pares d'alumnes i d'altres persones iniciaven al 1965 de forma clandestina l'Escola de Mestres "Rosa Sensat" de Barcelona-o la que recrea de forma commovedora Josefina Aldecoa (1995) a Historia de una maestra. Formen part d'un altre temps on la curiositat infantil encara no era assaltada pels mitjans audiovisuals (SARTORI, 2000). Ara els nens arriben a l'escola farts d'imatges, notícies i informacions a les quals abans s'hi accedia a poc a poc. La clau dels secrets de la naturalesa i el món la posseïen els adults, i el nen només podia esperar que arribés el moment per poder compartir-la.

L'eclipsi del mestre representa també l'eclipsi de la influència familiar (SAVATER, 1997). L'educació familiar és el primer pas perquè la socialització secundària, la que es realitza a l'escola, pugui funcionar. L'educació familiar funciona per via de l'exemple, amb una càrrega afectiva que està recolzada per mitjà de gestos, humors compartits, xantatges emocionals... És principalment en aquesta càrrega afectiva on resideix la seva força: l'amenaça de perdre l'estima dels pares.

Des de fa temps, els pares i les mares moderns han perdut els referents cap on dirigir l'afectivitat dels seus fills. L'autoaprenentatge infantil de l'autocontrol s'inicia amb les ordres i indicacions dels pares. Ells són els que ofereixen suport, però també resistència. Si pateixen la carència d'aquesta tutela, no sempre complaent, els fills perden el sentit de l'existència (Barudy, 1998).

La responsabilitat que tenen els pares i les mares quan les excuses sociològiques i del sistema ja no els eximeix de complir amb les seves obligacions passa, sobretot, per la qüestió de l'autoritat. Ens ho recordava Hannah Arendt (1968) en un polèmic assaig sobre la crisi contemporània de l'educació : "La autoridad ha sido abolida por los adultos y ello sólo puede significar una cosa: que los adultos se rehúsan a asumir la responsabilidad del mundo en el que han puesto a los niños" [Arendt, Hannah. La crisis de la educación. A Between Past and Future. Viking Press. New York. 1968. La citació es troba a Savater, Fernando op. cit. 10, (p. 108)].

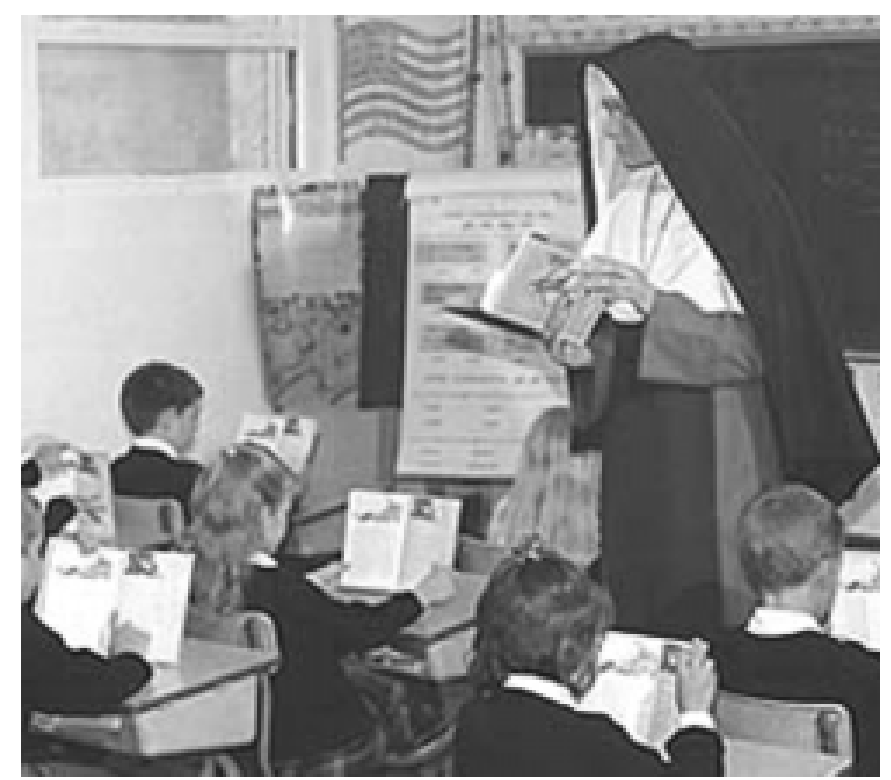

Aquesta dimissió familiar, que des de fa molts anys és sobretot paterna, repercuteix directament a l'escola. Així ho apuntava Juan Carlos Tedesco (1995): "Los docentes perciben este fenómeno cotidianamente, y una de sus quejas más recurrentes es que los niños acceden a la escuela con un núcleo básico de socialización insuficiente para encarar con éxito la tarea del aprendizaje. Para decirlo muy esquemáticamente, cuando la familia socializaba, la escuela podía ocuparse de enseñar. Ahora que la familia no cubre plenamente su papel socializador, la escuela no sólo puede efectuar 


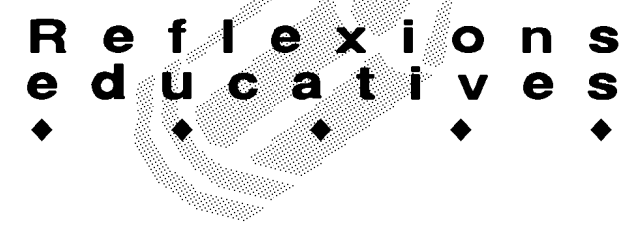

su tarea específica con la tarea del pasado, sino que comienza a ser objeto de nuevas demandas para las cuales no está preparada".

No tot pot resoldre's a l'escola ni compensar-se amb el bon ofici dels mestres: en aquestes qüestions l'escola no pot actuar al marge de l'entorn social i familiar del nen o de la nena, i encara menys a la contra, com un correctiu extern que multipliqui les seves pressions formatives mentre que la resta d'implicats deixen d'exercir-les.

Que sobre les escoles no hagi de caure la responsabilitat d'exercir aquestes funcions no vol dir que no hi esclatin els "efectes col-laterals". És en aquests moments quan determinats representants d'una pedagogia críptica i moderna aprofiten per anunciar noves estratègies d'intervenció que han de convertir els mestres en professionals eficaços. Carregats de paciència, aquests han de suportar un llenguatge fatu i pedant que al "pati" l'anomena "segment d'oci", la "tutoria" es converteix en una "negociació" i "l'ensenyança" en una "microseqüenciació curricular". Tots aquests barbarismes, com bé declara Savater, tan sols satisfan la vanitat dels qui els pronuncien, però aporten ben poc a la millora de la tasca docent.

Quan de vegades penso en aquella jove mestra del curs de preescolar de l'any 81 , em pregunto què la deu portar, encara avui, a seguir obrint la caixa de fusta dels guixos de colors per fascinar de nou els petits alumnes del segle XXI amb aquells dibuixos desconeguts i plens de significat que els acompanyaran la resta de les seves vides.

Que estrany aquest ofici de la mestra i el mestre en un món tan difícil de comprendre! Són els primers que arriben a l'escola plens de contradiccions, però davant es troben alumnes que esperen d'ells alguna certesa que ompli de sentit la seva identitat, o els faci dubtar.

Sí!, la mestra o el mestre tanquen la porta de l'aula i allí es queden sols davant d'unes petites persones que no ho han pogut triar... L'escola és obligatòria, així que els correspon apropar els seus alumnes a la virtut de la formació. I han de saber que aquesta virtut no rau en el contingut de les seves ensenyances, o de les seves assignatures, sinó en la seva personalitat, en la manera d'impartir-les.

El seu ofici, a pesar dels discursos d'alguns petulants, depèn de la seva capacitat per exercitar-lo amb art $i$ sensatesa. Erigir la seva ascendència sobre els que l'atenen significa haver de seduir sense hipnotitzar (FILLOUX, 2000). Savater segueix recordant-nos quantes vegades la vocació de l'alumne es desperta més per adhesió a un mestre o a una mestra preferits que per la matèria que imparteixen: "quizá la excesiva personalidad del maestro pueda dificultar o aun pervertir su función de mediador social ante los jóvenes, pero tengo por indudable que sin una cierta personalidad el maestro deja de serlo y se convierte en desganado gramófono o en policía ocasional. Es el momento de recordar que la pedagogía tiene mucho más de arte que de ciencia, es decir, que admite consejos y técnicas pero que nunca domina más que por el ejercicio mismo de cada día, que tanto debe en los casos más afortunados a la intuición". (p. 111).

Recordo un altre moment, aquest cop en el curs de segon d'EGB del 82. Un mestre nou va fer-se càrrec del nostre grup en substitució de la nostra tutora. Era l'època que els grans herois de la programació infantil de la televisió eren D'Artagnan i els tres mosqueters. Un dia, a l'hora de plàstica, vàrem decidir construir espases de plastilina. Simulàvem duels entre nosaltres imitant aquelles aventures. Se sentien crits, alguns pujaven sobre les taules i les cadires, d'altres queien ferits a terra... El director de l'escola va entrar de sobte a l'aula. Era un home sever, excessivament preocupat per l'ordre i la disciplina. El nostre mestre estava de peu a la taula del professor mentre mantenia un duel amb tres companys que l'assetjaven. El director li va cridar l'atenció davant nostre: -iUsted no está teniendo en cuenta los contenidos actitudinales y procedimentales!...

\section{Referències bibliogràfiques}

ALDECOA, J. Historia de una maestra. Ed. Anagrama. Barcelona. 1995.

BARUDY, J. El dolor invisible de la infancia. Ed. Paidós. Barcelona. 1998.

BLOOM, A. El cierre de la mente moderna. Ed. Plaza \& Janés. Barcelona. 1998.

CAMUS, A. Elprimer hombre. Ed. Tusquets. Barcelona. 1994 CAMUS, A. El mito de Sísifo. Obras, 1. Alianza Editorial. Madrid. 1996.

FILLOUX, JC. Campo pedagógico y psicoanálisis. Ediciones Nueva Visión. Buenos Aires. 2000.

HARO TECGLEN, E. El niño republicano. Ed. Alfaguara. Madrid. 1996.

RIVAS, M. La lengua de las mariposas. A ¿Qué me quieres, amor?. Ed. Santillana. Madrid. 1998.

SÁBATO, E. Antes del fin. Ed. Seix Barral. Barcelona. 1999.

SARTORI, G. Homo videns. La sociedad teledirigida. Ed. Taurus. Madrid. 2000.

SAVATER, F. El valor de educar. Ed. Ariel. Barcelona. 1997.

TEDESCO, JC. El nuevo pacto educativo. Ed. Anaya. Madrid. 1995.

\section{Filmografia} España.

CUERDA, José Luis (1999): La lengua de las mariposas. 